\title{
The Impact of Education Based on Health Belief Model on Mam- mography among Bushehrian Teachers
}

Farideh Esmaili

MSc in Health Education, Dept. of Health Education \& Health Promotion, School of Health, Bushehr Province University of Medical Sciences (BPUMS), Bushehr, Iran Esmat Heydari

MSc of Health Education \& Health Promotion, School of Health, Bushehr University of Medical Sciences (BPUMS), Bushehr, Iran

\section{Azita Noorozi}

* Associate Prof., Dept. of Health Education \& Health Promotion, School of Health, \& Researcher of the Persian Gulf Tropical Medicine Research Center (PGTMRC), BPUMS, Bushehr, Iran (Corresponding author) azitanoroozi@ yahoo.com

Rahim Tahmasebi

Associate Prof., Dept. of Biostatistics, School of Health, \& Researcher of the Persian Gulf Tropical Medicine Research Center (PGTMRC), BPUMS, Bushehr, Iran

Received: 25 November 2015

Accepted: 16 November 2016

\section{ABSTRACT}

Background and objective: Breast cancer is the most common cancer among women. One of the ways to decrease the death due to breast cancer is early detection through mammography. This study considered the impact of education based on Health Belief Model (HBM) on teachers using mammography in Bushehr.

Materials and methods: The current study was a random clinical trial which included of 120 teachers over 40 years old. The teachers were randomly divided in two groups. The teachers of intervention group received two sessions education based on HBM. Both groups fill out the Champion Questionnaire before, immediately and three months after education. Mammography performance considered before and three months after study in two groups.

Results: The comparison of mean scores of constructs between two groups showed significant difference in knowledge, perceived benefits, perceived barriers and health motivation $(p<0.05)$, but there was no significant difference in perceived susceptibility and severity $(p>0.05)$. Mammography performance increased significantly in the intervention group $(p<0.001)$.

Conclusion: Group education with limited sessions had desirable effect in increasing knowledge of teachers about breast cancer and mammography performance. So, it is recommended to design and perform the group education programs based on HBM for women from different groups.

Paper Type: Research Article.

Keywords: Mammography, Breast Cancer, Health Belief Model (HBM), Group Education, Teachers, Bushehr.

Citation: Heydari M, Noorozi A, Tahmasebi R. The impact of education based on health belief model on mammography among Bushehrian teachers. Iran J Health Educ Health Promot. Winter 2016;4(4): 271-280. 


\section{جكيده}

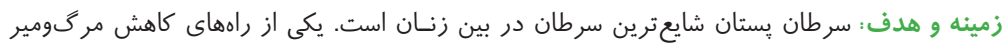

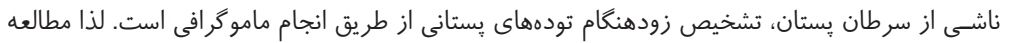
حاضر با هدف تعيين تأثير آموزش مبتنى بر الكوى اعتقاد بهداشتى در انجام ماموكر افى بين معلمان شهر التهر

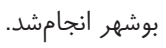

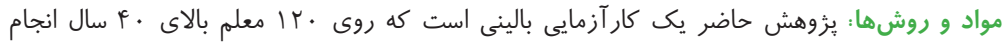

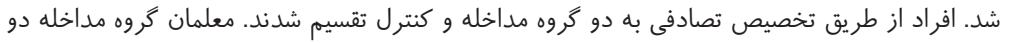

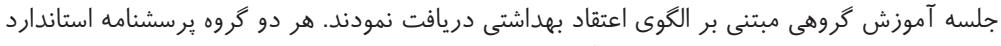

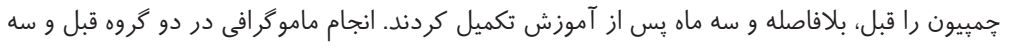

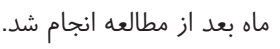

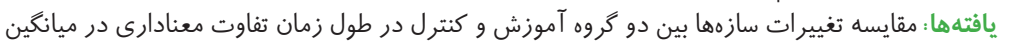

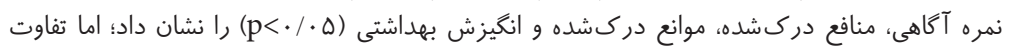

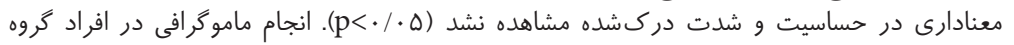

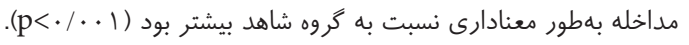

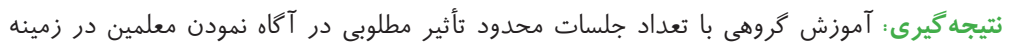

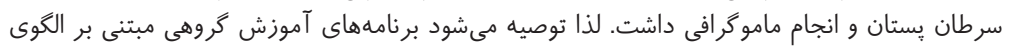

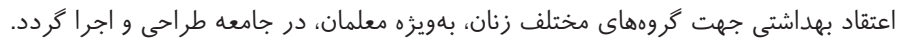

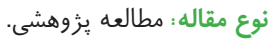

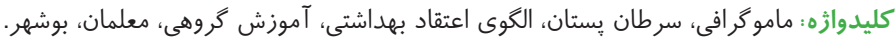

> استناد : حيدرى ع، نوروزى آ، طهماسبى ر. تأثير آموزش مبتنى بر الخوى اعتقاد بهداشتى بر انجام

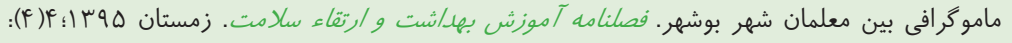
rर. $-4 \vee 1$

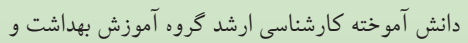

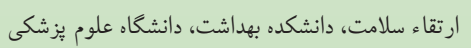

$$
\text { بوشهر، بوشهر، ايران }
$$

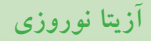

* * دانشيار كروه آموزش بهداشت و ارتقاء سلامت،

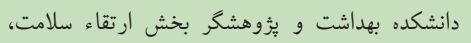

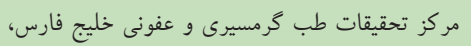

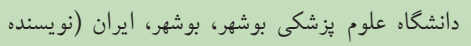

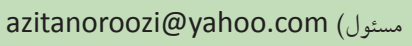

$$
\text { رحيم طهماسبى }
$$

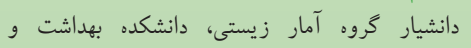

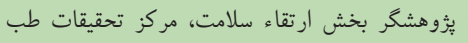

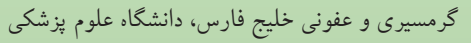
بوشهر، بوشهر، ايران

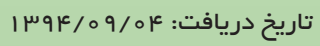

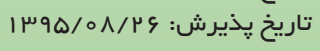


راستا، باورها در زمينه برنامهاى غربالكرى بر انجام رفتار مقدمه

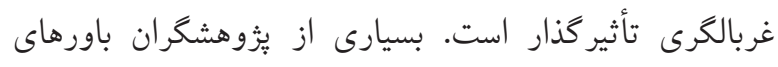

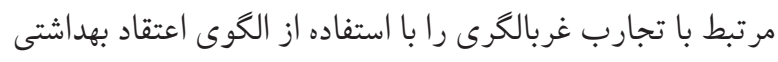

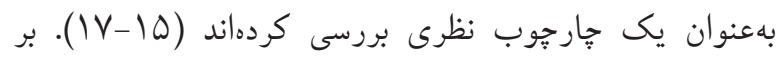

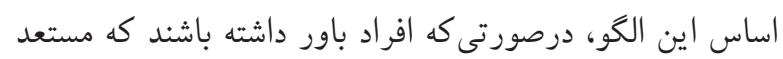

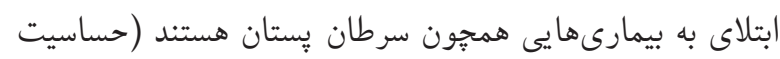

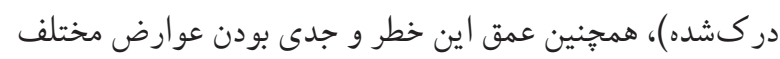

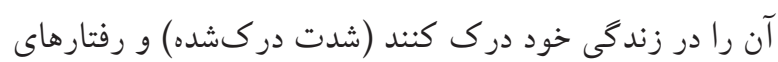

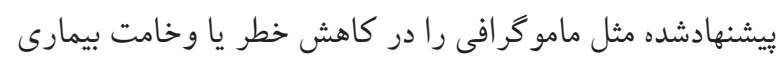

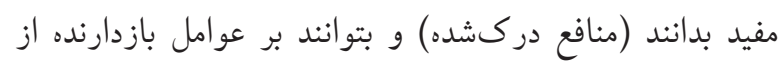
عمل همجِون هزينه، درد و ...غلبه كنند (موانع دركشده)، تمايل

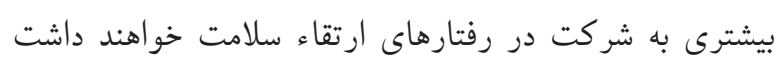
. (19-11) طبق مطالعه هاتفـيا و همكاران (·怆) در خصوص تأثير آموزش گروهى در زمينه سرطان پِّتان و انجام ماموكرافى،

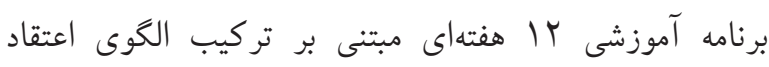

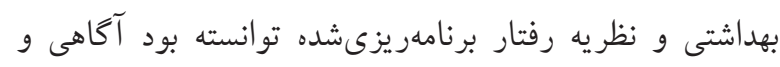

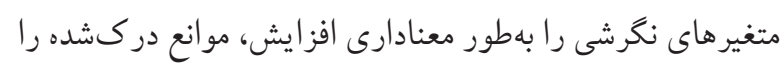

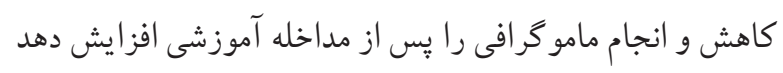

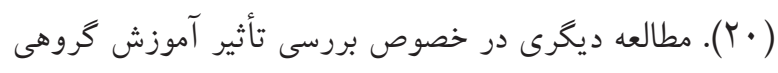
بر آكاهى، نكرش و عملكرد زنان توسط خليلى و همكاران

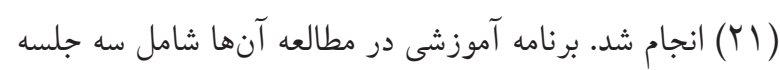
آموزشى يكساعته بود. نتايج مطالعه آنها نشان داد كه در كروه آموزش علاوه بر افزايش ميانكين آكاهى و سازههاى الكوى يكان

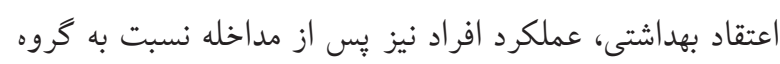

كنترل افزايش يافته بود (T) (Y).

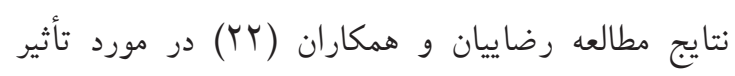

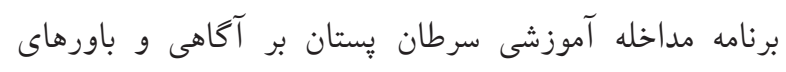

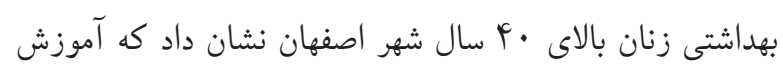

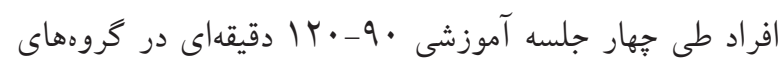

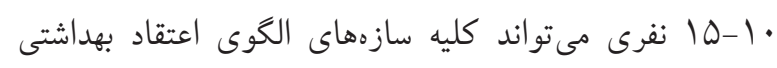

سرطان پِتان شايعترين سرطان در بين زنـان بوده و درصد

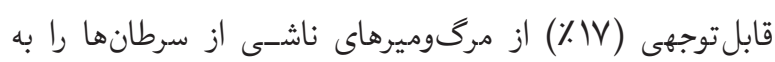
خود اختصاص مى دهد ( (1). در واقع، يّ از سرطان ريسه سرطان

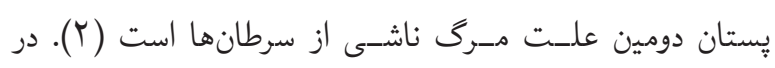

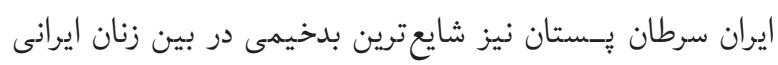

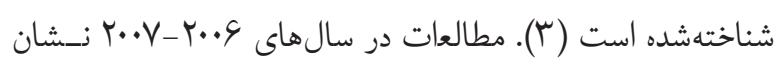

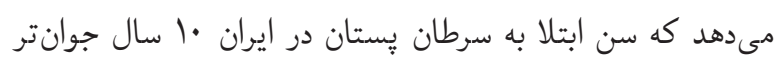

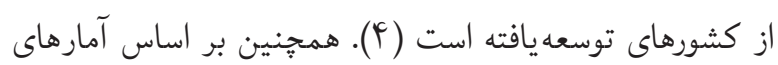

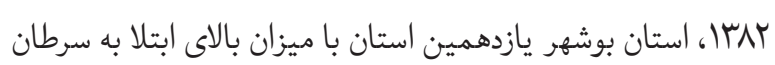
يستان در كشور محسوب مىشود (ه).

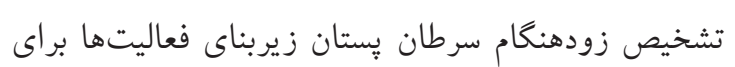
كاهش مرگومير ناشسى از اين بيمارى است. مطالعات موجود زئن

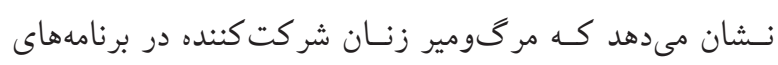

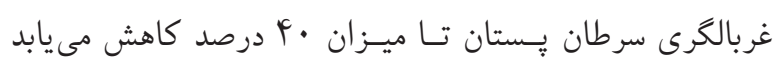

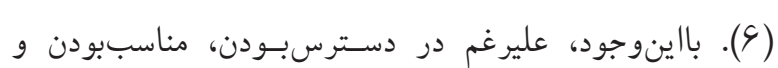

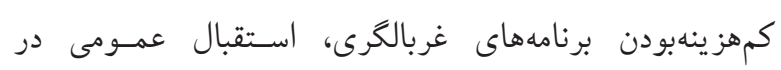

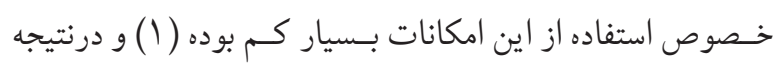
شانس بقاى زنان كم است؛ بهطورى كه از هر جهار زن مبتلا در

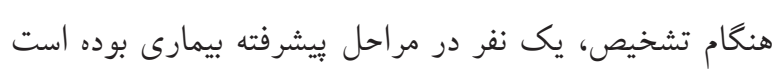
.( $(\wedge-\mathrm{V})$

طى تحقيقات بهعمل آمده خودآزمايى بـتان، ماموكرافى

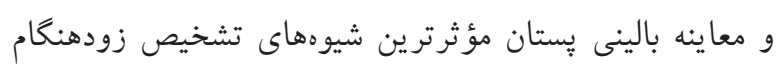

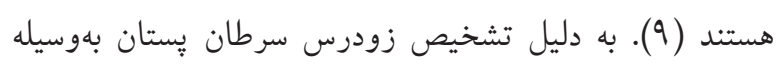

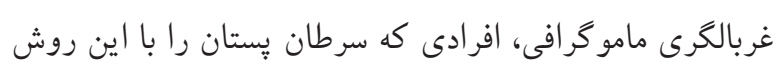
تشخيص دادهاند، از ميزان موفقيت درمان بالايى بهره بردهاند

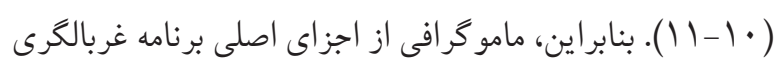

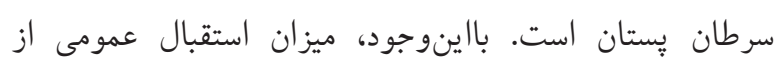

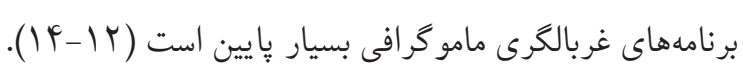

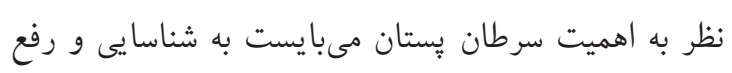

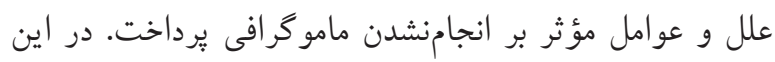


افراد نمونه در دو گروه مداخله (آموزش گروهى) و كنترل

در سطح مدرسه بهطور تصادفى اختصاص داده شدند. بدين ترتيب

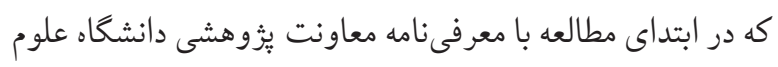

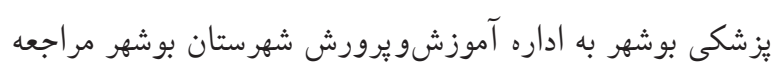

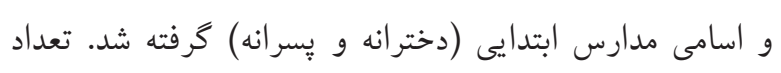

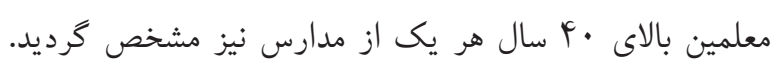

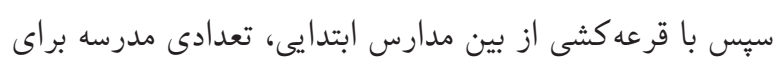

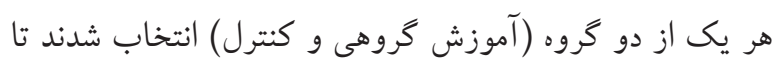
جايى كه حجم نمونه لازم براى هر كروه ( •9 نفر) تأمين كرديد.

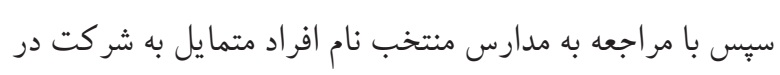

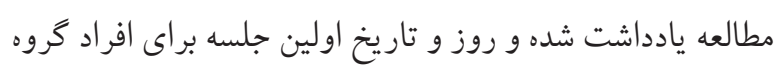
آموزشى تعيين شد.

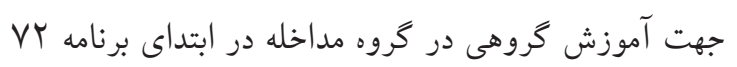

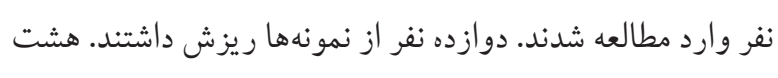

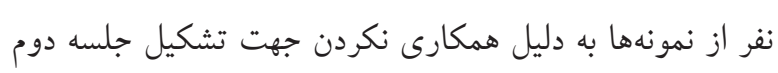

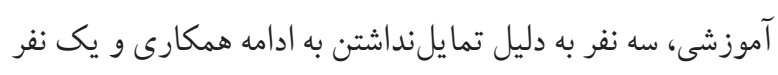

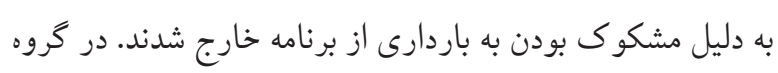

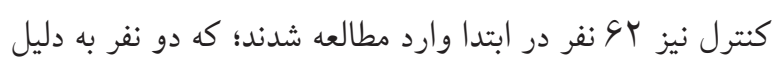
تمايل نداشتن به ادامه مشار كت مطالعه را ترى كردند. يس از كسب رضايت كتبى از افراد كروه مداخله (آموزش

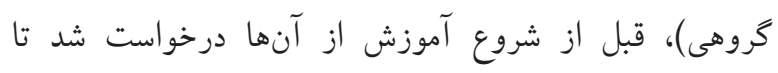

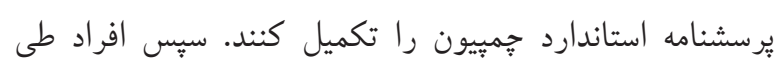
دو جلسه آموزش گروهى يك ساعته با فاصله زمانى يك هفته

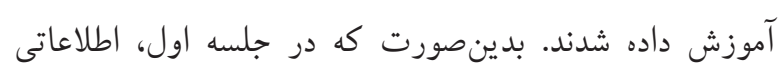

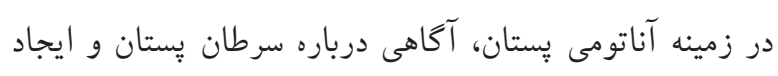
احساس خطر در برابر سرطان پِتان (افزايش حساسيت) ارائه شد. افراد با ذكر نمونههايى از دوستان و آشنايان كه بدون داشتن مشكل خاصى در سلامت خود و يا سابقه ابتلا به سرطان در اعضاى خانواده خود، دجار سرطان پِّتان (يا ساير سرطانها) شده بودند، در هم گروههاى خود ايجاد حساسيت مى كردند و در

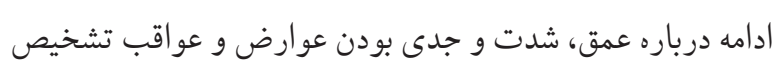

را بهور معنادارى افزايش دهد. در مطالعه ديخرى كه كريمى

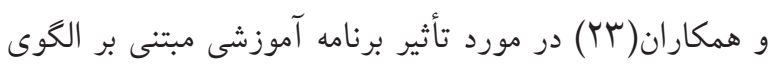

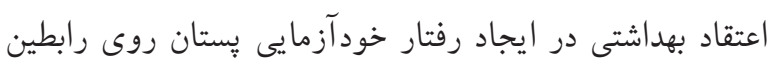

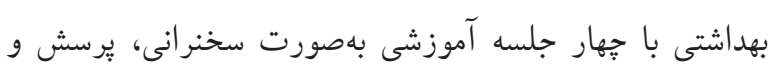

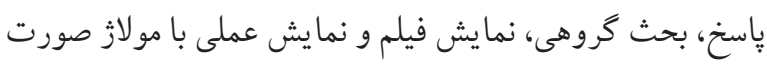

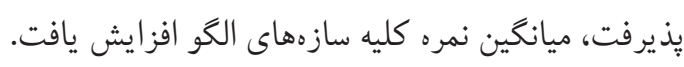

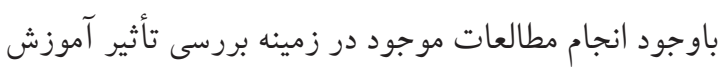

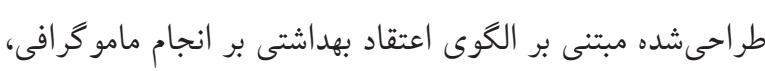

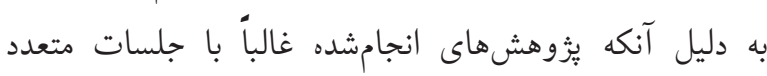

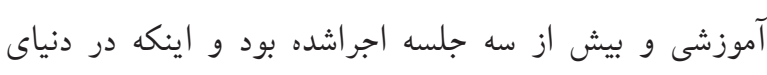

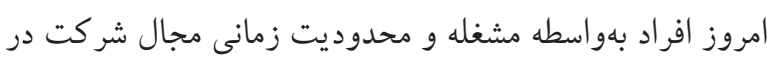

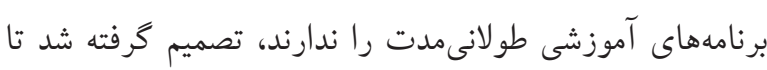

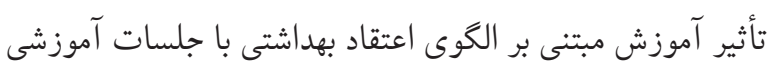

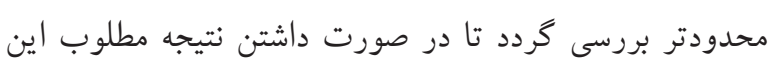

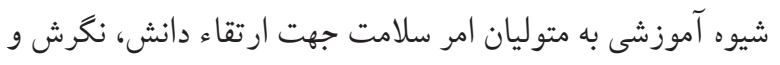
عملكرد زنان جامعه يِيشنهاد كردد. مو اد و روش ها يزوهش حاضر يك كارآزمايى بالينى تصادفى بود كه از آذر تا

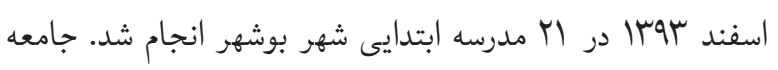

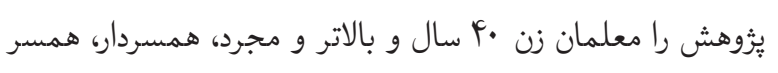
مرده يا مطلقه شاغل در مدارس ابتدايى شهر بوشهر تشكيل

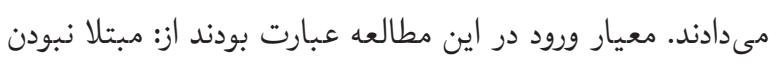

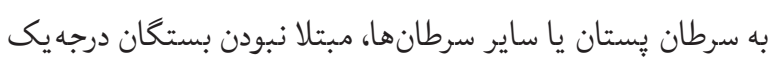

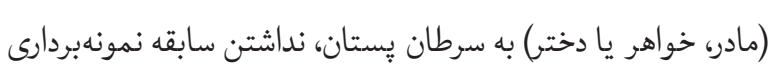

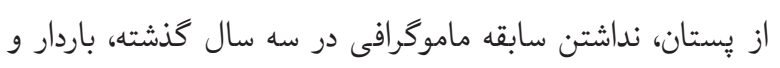

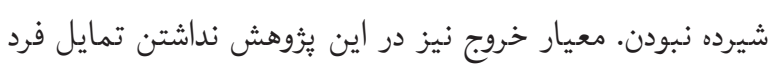

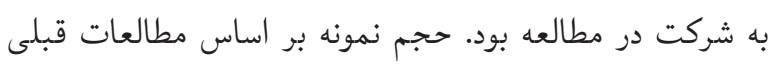
تعداد Or (IV)

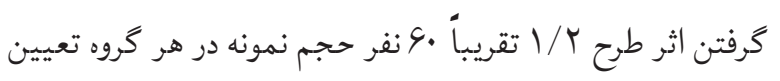
شد. 


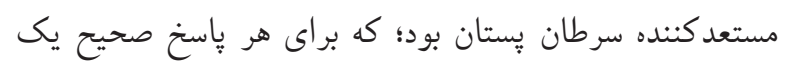

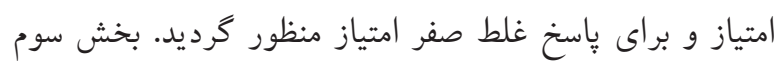

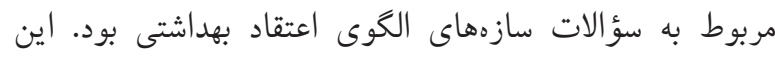
بخش حاوى • r سؤال در رابطه با باورهاى فرد درباره حساسيت

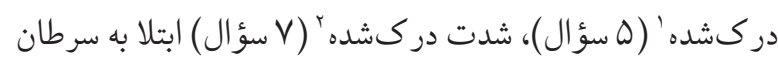

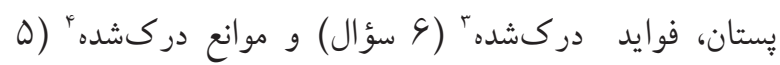

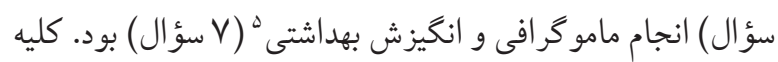

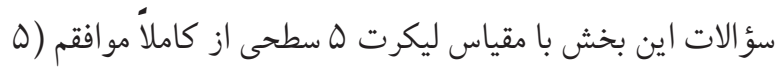

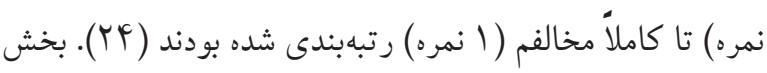

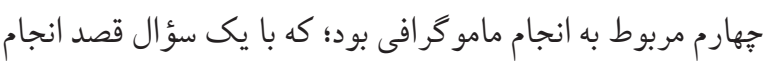

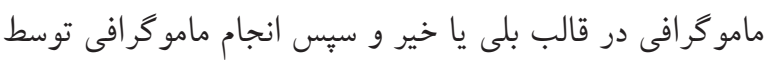
افراد موردبر رسى قرار كرفت.

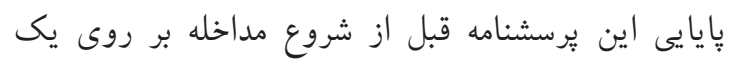

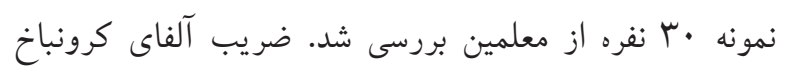

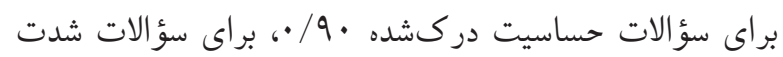

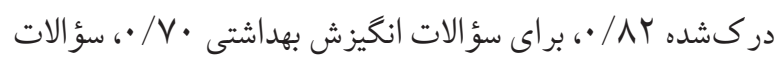

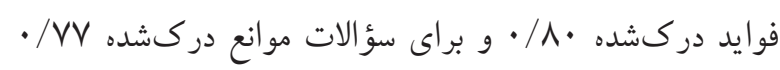

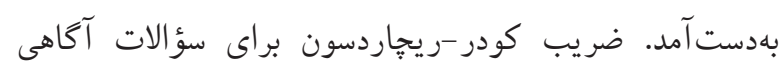
/VA

جهت رعايت اصول اخلاقى، اهداف مطالعه بهصورت شفاهى بر برد

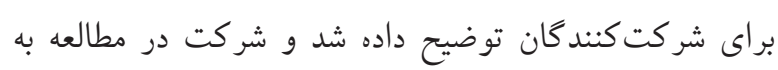

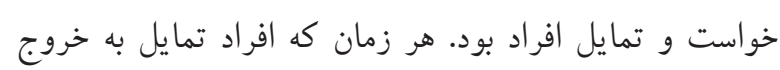
از مطالعه داشتند، اجبارى جهت ادامه مطالعه وجود نداشت.

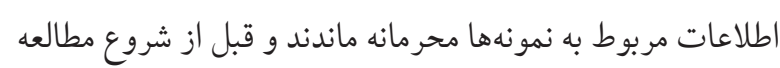

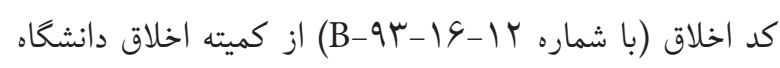

$$
\text { علوم يزشكى بوشهر دريافت كرديد. }
$$

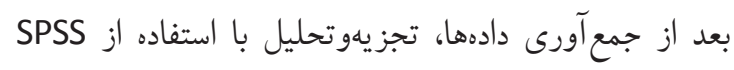

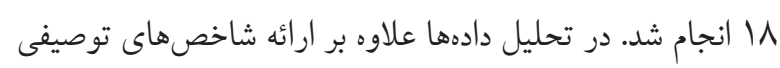

\footnotetext{
1. Perceived Susceptibility

2. Perceived Severity

3. Perceived Benefits

4. Barriers Perceived

5. Health Motivation
}

ديررس بيمارى (شدت دركشده) مطالبى ارائه شد و از افرادى كه در مورد حساسيت ابرازنظركرده بودند خواسته مىشد تا اثرات فردى، خانوادگى و مالى سرطان را در نمونههايى كه درباره آنها صحبت كرده بودند توضيح دهند. در پايان جلسه، جمع بندى ورى اطلاعات توسط سخنرانى و با استفاده از پاور بو ينت انجام شد. با فاصله يك هفته، در جلسه دوم ابتدا درباره كارايى

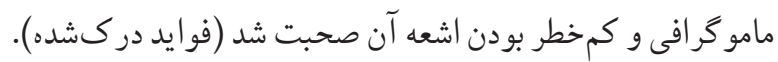

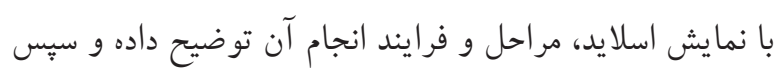

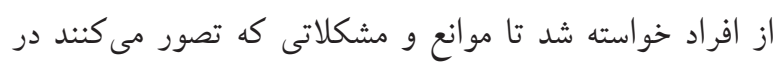

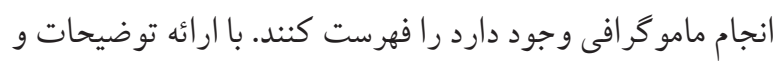
راهنمايى هايى سعى در رفع موانع شد. در اين جلسه فواصل زمانى وردي

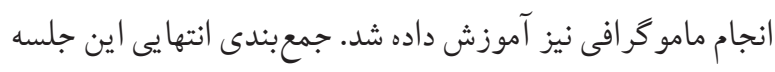

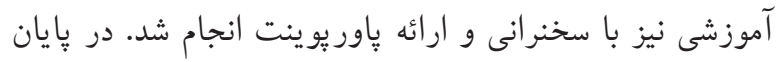

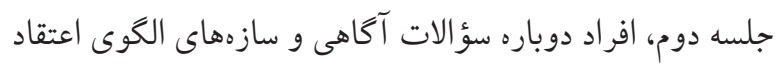

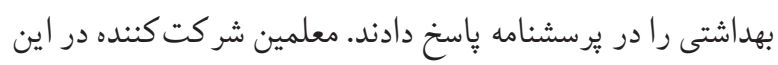

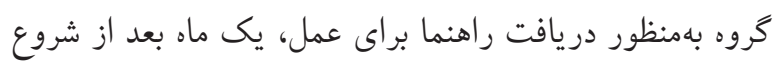

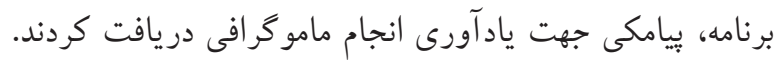

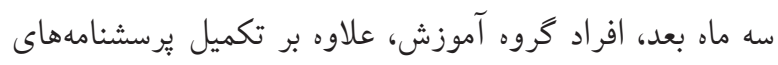
آكاهى و سازهاى الكوى اعتقاد بهداشتى، ازنظر انجام يا انجام

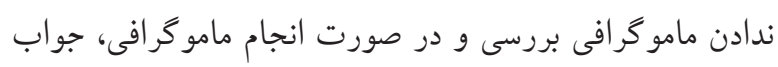

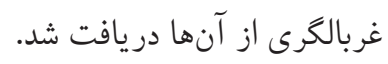
در اين مطالعه، افراد گروه كنترل هيج گونه آموزشى اعم از

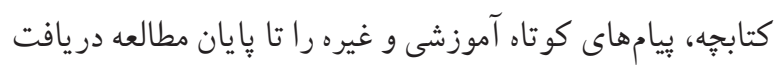

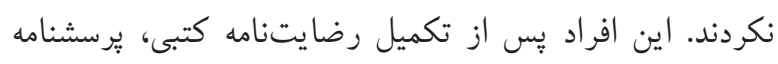

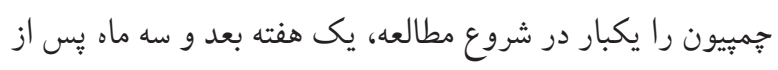
شروع مطالعه تكميل نمودند.

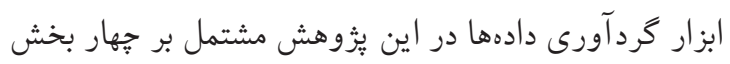
بود. بخش اول شامل مشخصات فردى با · r سؤال (سن، ميزان تحصيلات خود و همسر، وضعيت ازدواج، تعداد باردارى و تعداد

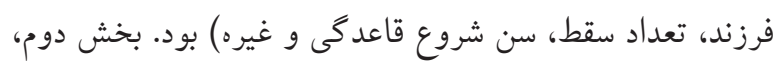

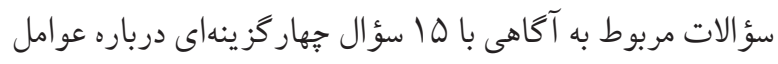


از آزمونهاى كاى اسكوئر و دقيق فيشر بهمنظور مقايسه وضعيت متغيرهاى جمعيتشناختى كيفى بين گروههاى آموزشى، آزمون (

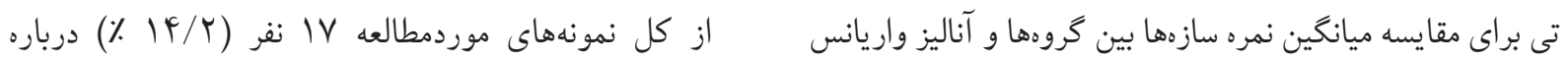

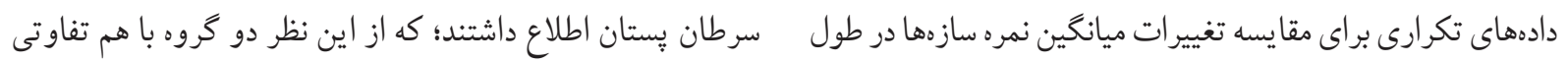

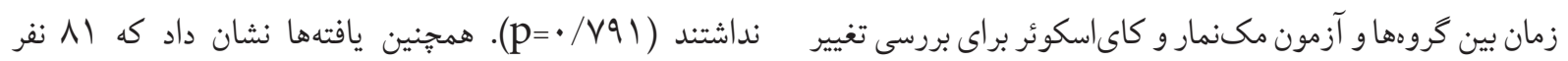

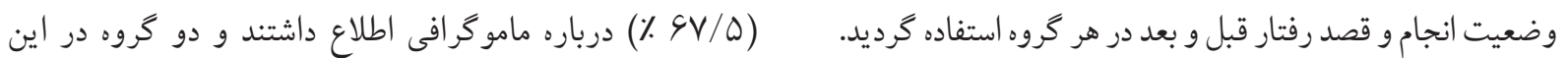

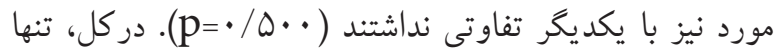

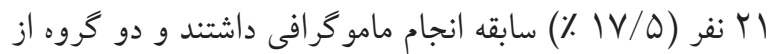
بافتهه

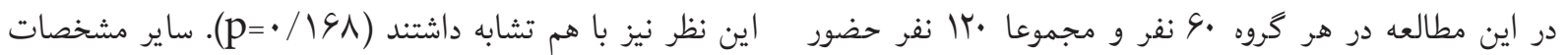

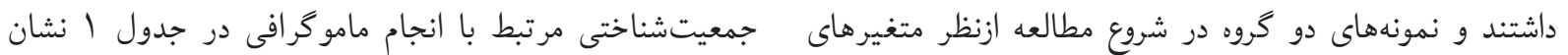

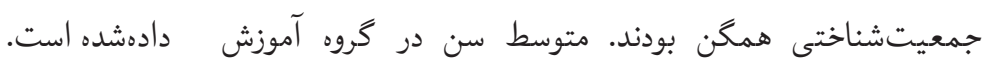
جدول ا. مشخصات جمعيتشناختى و رفتار غربالكَرى سرطان پِّتان در شروع مطالعه

\begin{tabular}{|c|c|c|c|c|c|c|}
\hline \multirow{2}{*}{$\begin{array}{l}\text { p value } \\
. / 10\end{array}$} & \multirow{2}{*}{$\begin{array}{l}r x \\
r / \wedge \cdot 1\end{array}$} & \multicolumn{2}{|c|}{ تعداد كروه كنترل درصد } & \multicolumn{2}{|c|}{ تعداد آموزش گروهى } & \\
\hline & & $\begin{array}{l}\Lambda \varepsilon / \mathrm{V} \\
1 \cdot \\
\mu / \mu\end{array}$ & $\begin{array}{c}\Delta r \\
q \\
r\end{array}$ & $\begin{array}{l}90 \\
1 / V \\
\mu / \mu\end{array}$ & $\begin{array}{l}\Delta V \\
1 \\
r\end{array}$ & وضئ متأهل تأهل \\
\hline - $/ \mathrm{V} I F$ &.$/ I \mu F$ & $\begin{array}{l}F N / \mu \\
\Delta 1 / V\end{array}$ & $\begin{array}{l}r q \\
r\end{array}$ & $\begin{array}{l}i \Delta \\
\Delta \Delta\end{array}$ & $\begin{array}{l}r v \\
r \mu\end{array}$ & $\begin{array}{c}\text { كاردانى، كارشناسى وضيت تحصيلى بالاتر } \\
\text { وضيلى }\end{array}$ \\
\hline$\cdot / \mu Y Y$ & . $/ F \mu s$ & $\begin{array}{l}G / V \\
q \pi / r\end{array}$ & $\begin{array}{l}r \\
\Delta S\end{array}$ & $\begin{array}{l}1 . \\
9 .\end{array}$ & $\begin{array}{c}q \\
\Delta F\end{array}$ & سابقه سرطان بِستان در خانواده \\
\hline$\cdot / V 91$ &.$/ q V$. & $\begin{array}{l}1 \mu / \mu \\
1 \cdot \\
V S / V\end{array}$ & $\begin{array}{l}1 \\
4 \\
4 \varphi\end{array}$ & $\begin{array}{l}10 \\
S / V \\
V N / r\end{array}$ & $\begin{array}{l}q \\
q \\
p v\end{array}$ & 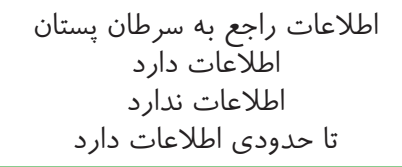 \\
\hline$\cdot 10$. & $\cdot / \cdot r \Lambda$ & $\begin{array}{l}94 / V \\
\mu \mu / \mu\end{array}$ & $\begin{array}{l}r . \\
r .\end{array}$ & $\begin{array}{l}S \Lambda / \mu \\
\mu_{1 / V}\end{array}$ & $\begin{array}{l}41 \\
19\end{array}$ & 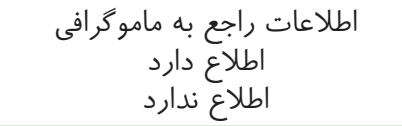 \\
\hline$\cdot / 191$ & $1 / F \mu \mu$ & $\begin{array}{l}1 \mu / \mu \\
\Lambda s / V\end{array}$ & $\hat{\Delta r}$ & $\begin{array}{l}r \mid / V \\
V N / r\end{array}$ & $\begin{array}{l}\text { Ir } \\
q V\end{array}$ & خبل خيله \\
\hline$\cdot / \mu \Delta \Delta$ & $\cdot / \pi /$. & $\begin{array}{l}S 1 / V \\
\mu N / \mu\end{array}$ & $\begin{array}{l}r v \\
r \mu\end{array}$ & $\begin{array}{l}\Delta S / V \\
\hat{F} / \mu\end{array}$ & $\begin{array}{l}\text { ru } \\
r s\end{array}$ & اطلاعات راجع به خودآزمايى يستان \\
\hline.$/ \Delta V Y$ & $\cdot|\cdot| 1\rangle$ & $\begin{array}{l}\Delta . \\
\Delta .\end{array}$ & r. & $\begin{array}{l}0 . \\
0 .\end{array}$ & $\begin{array}{l}\mu . \\
\mu .\end{array}$ & 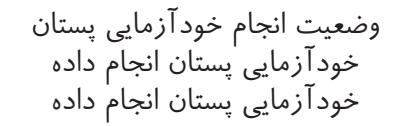 \\
\hline
\end{tabular}


زنان در گروه آموزش و گروه كنترل ازنظر آكاهى و باورهاى بودند؛ اما اختلاف معنادارى در برخى از سازهها يّ از مداخله

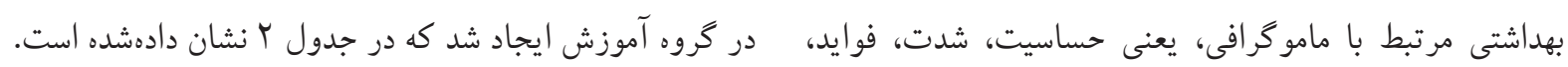

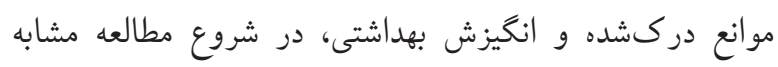

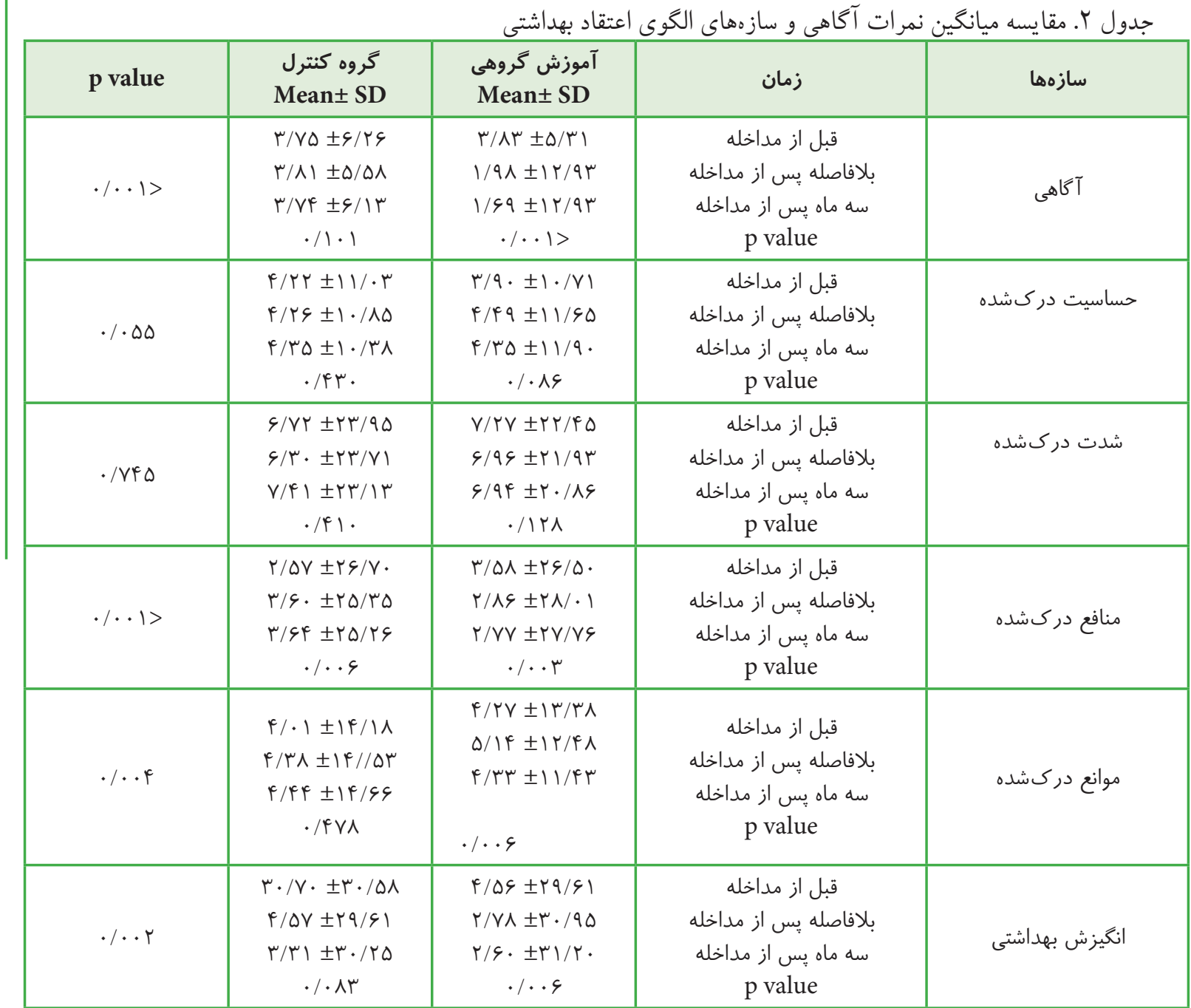

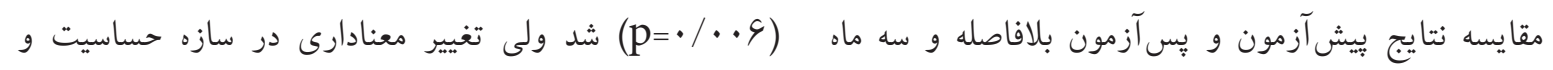

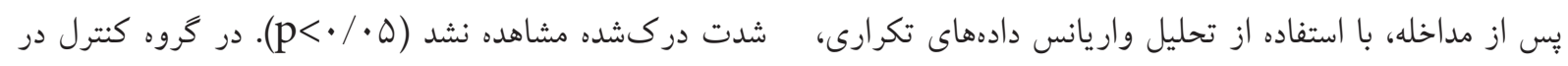

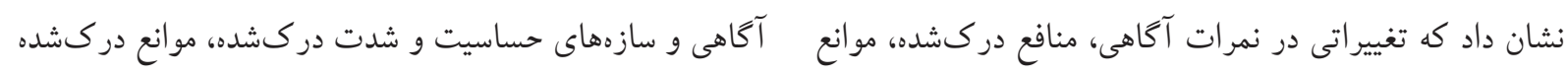

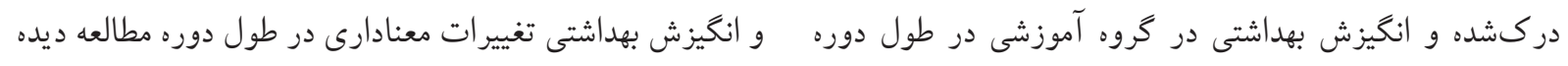

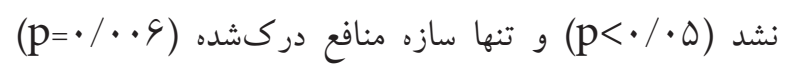
مطالعه رخد داده است.

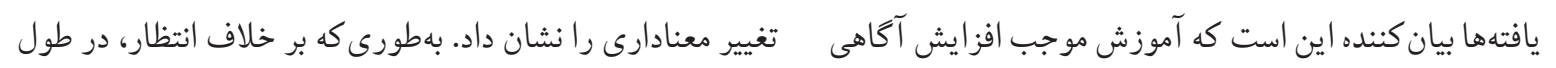

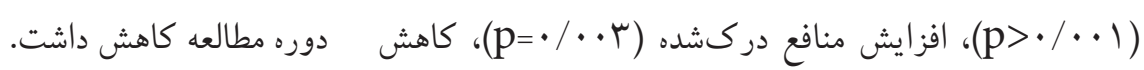

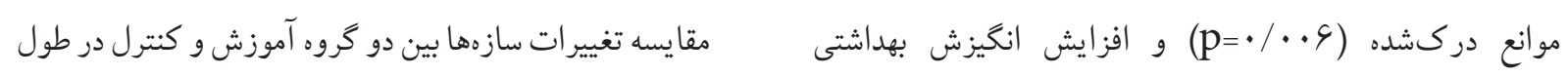


ازنظر حساسيت و شدت دركشده، معلمين ايرانى قبل و بعد از آموزش درك متوسطى از شدت بيمارى داشتند. دليل

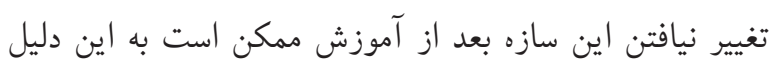

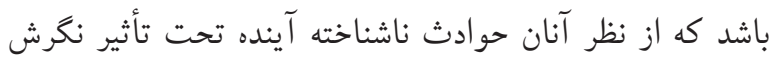

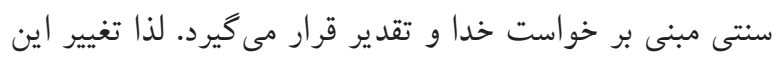

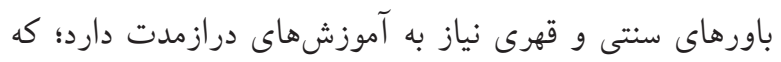

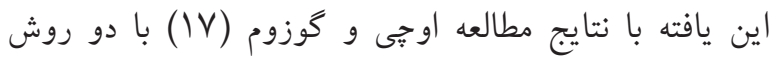

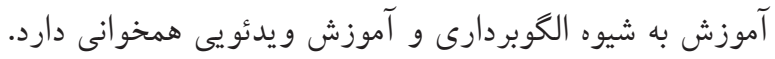

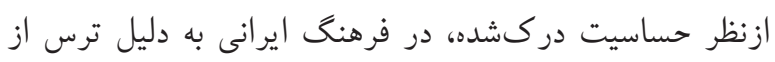
سرطان افراد استعداد ابتلا به بيمارى خود را انكار مى كنند. لذا

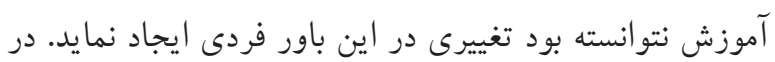

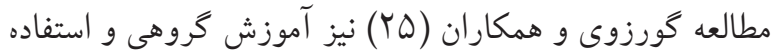
از مواد جإيى نتوانسته بود تغييرى در حساسيت و شدت درك ششده

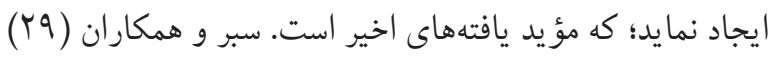

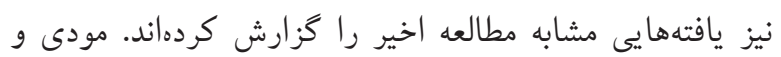

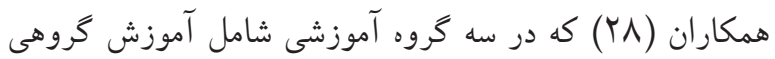

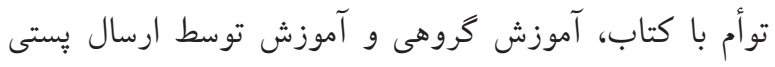

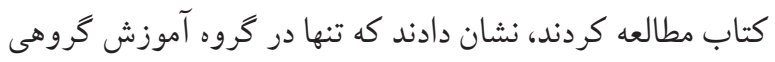

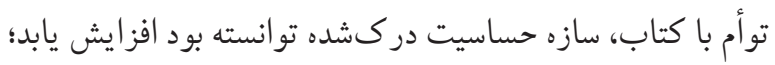
درحالى كه در دو كروه ديكر تغيير معنادارى نداشته و شدت

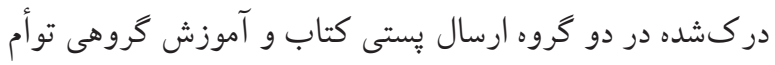
با كتاب تغيير معنادارى داشته است. بعلاوه در مطالعه رضاييان و همكاران (YY) كه آموزش با تعداد جلسات بيشترى انجام

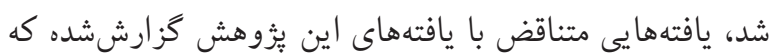

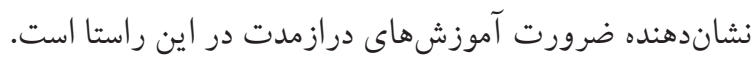
ازنظر فوايد در كشده، آموزش كروهى همر اه با با بحث توانسته

بود در طول زمان، درك افراد از فوايد مامو كر افى را ارتقاء دهدي؛

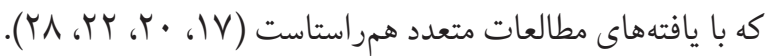

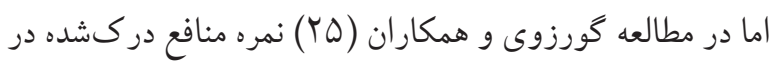
آموزش گروهى برخلاف مطالعه اخير افزايش معنادار نداشت؛ كه

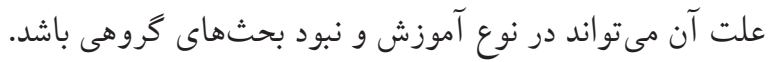

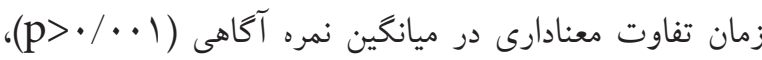

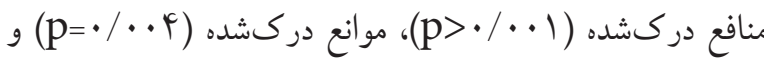

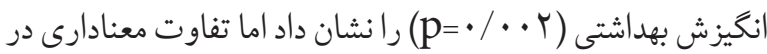

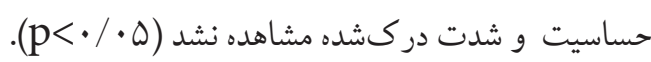
درباره قصد انجام مامو گرافى از •و شركت كننده در هر كروهاه

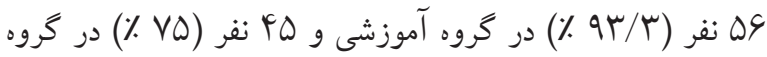

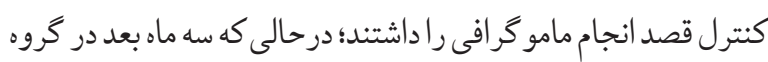

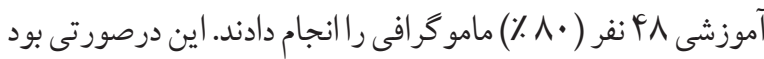
كه در كروه كنترل هيجيك از شر كت كنند كان مامو كر افى را انجام

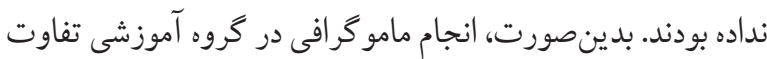

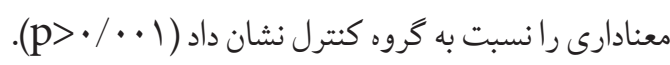

در ثُوهش حاضر كه تأثير آموزش مبتنى بر الكوى اعتقاد

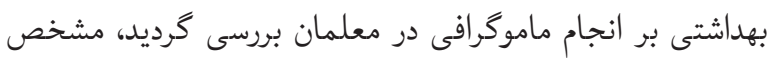

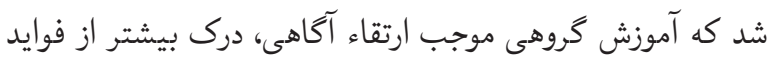

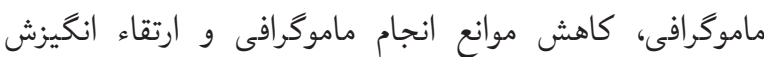

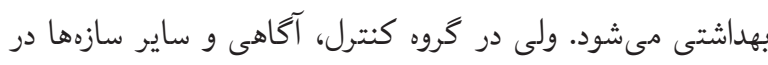
طول زمان تغييرى نكرده بود؛ بهجز منافع دركشده كه كاهش يافته

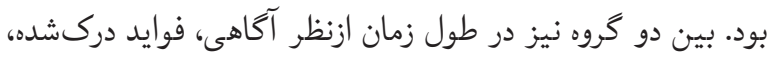

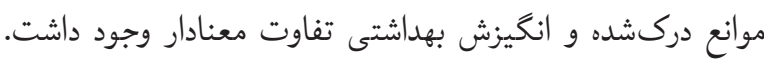
بهطورى كه آموزش كروهى موجب افزايش آكاهى، افزايش فوايد

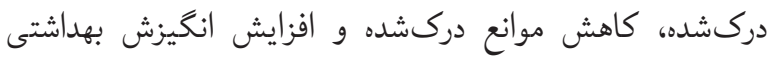
كرديد. ازنظر قصد انجام ماموكرافى، تمايل به انجام ماموكرافى در درد افراد تحت آموزش بهطور معنادارى بيشتر بود؛ همجنان كه سه ماه ماه

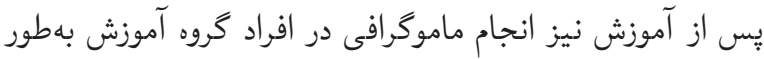
معنادارى بيش از كروه كنترل بود.

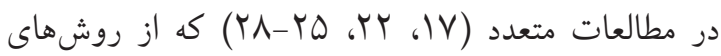

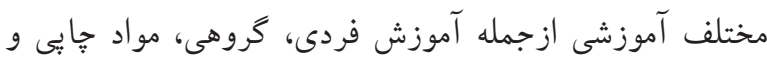

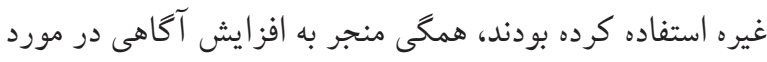
سرطان پستان شده بود؛ كه با يافتهاى مطالعه اخير همراستاست. 
با فواصل زمانى بيشتر اقدام به تكميل برسشنامهها كنند.

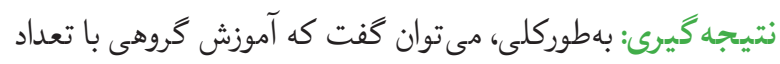
جلسات محدودتر (دو جلسه) نيز مى تواند تأثير مطلوبى در آكاه

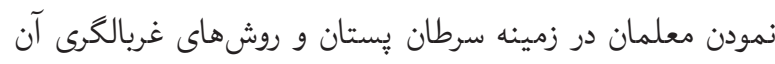

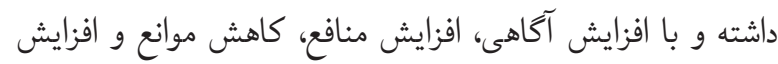
انكيزش بهداشتى نقش جشمخيرى در ايجاد قصد انجام ماموكرافى إنى

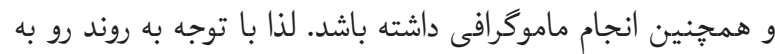
رشد موارد ابتلا سرطان يستان در كشور و نظر به نتايج مطالعات انجامشده در اين زمينه كه كماكان، نشان از پاييين بودن آمار غربالكرى ها دارد و نيز نتايج مطالعه حاضر و مطالعات مشابه كه دهان

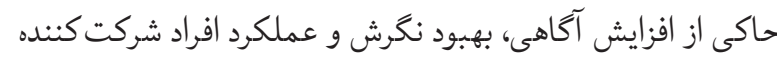
در آموزشهاى گروهى است. بنابراين، توصيه مى شود برنامههاى

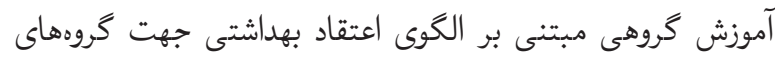
مختلف زنان در جامعه طراحى و اجرا گردد.

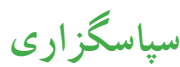

اين يُوهش بركرفته از پِايانامه مقطع كارشناسىارشد آموزش

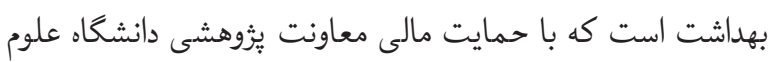
يزشكى بوشهر انجام شده است. بدينوسيله نويسندگان مقاله بر خود

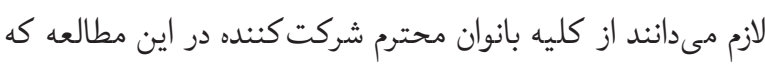
صبورانه در اين مطالعه شركت كردند تشكر و قدردانى مى كنند.

\section{References:}

1. Ryan KJ, Berkowitz RS, Barbieri RL, Dunaif AE. Kistner's gynecology and women's Health. Translated by Ghazijahani B. Tehran: Golban publishers; 2008. P. 229-248

2. Mahoori KH, Sadeghi HA, Abdorrasool T. Knowledge and practice of women referring to Shiraz health centers about breast cancer screening. Hormozgan Med J 2003; 7 (2): 68-75.

3. Moghadam F. Teachers knowledge and attitude of breast self-examination in high schools of Khoycity. MSc thesis in midwifery, Tabriz: Faculty of nursing and midwifery, Tabriz University of Medical sciences,1998.

4. Shahnazi M, Sahar A, Ghavami M. Breast cancer screening methods in women referring to educational centers of Tabriz 2006-2007. Abstract of papers; 13th international medical sciences Congress of Islamic Azad University, 2008: 133.
ازنظر موانع دركشده، معلمين در هر دو كروه، بيمه بهداشتى

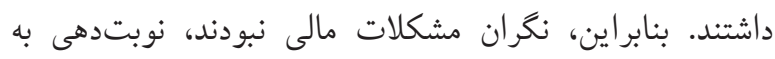

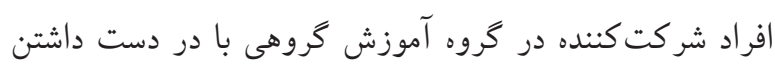

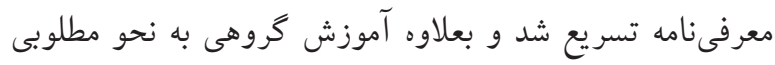

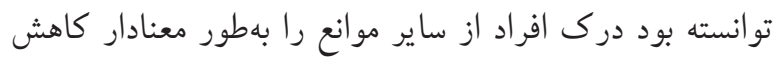

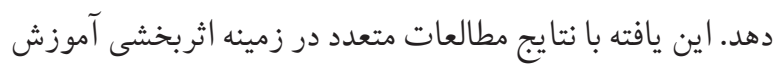

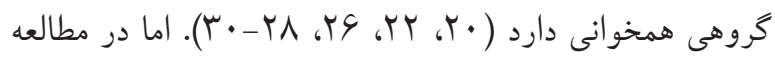

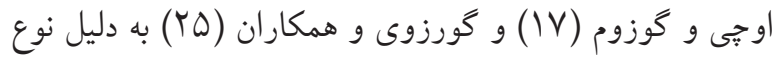
خاص آموزش و در نظر نكرفتن تمهيدات بكار رفته شده در اين

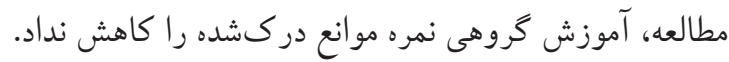

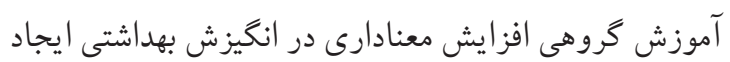

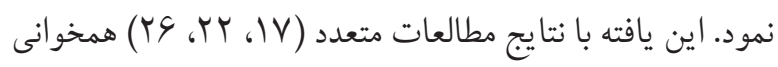
دارد. آموزش كروهى توانسته بود منجر به قصد انجام مامو كرافى آنى

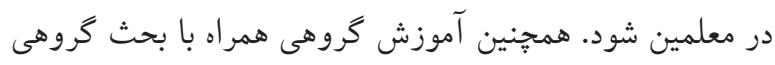

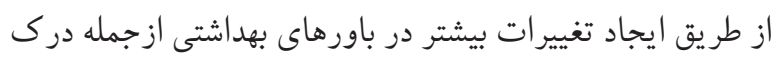

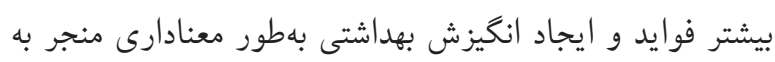

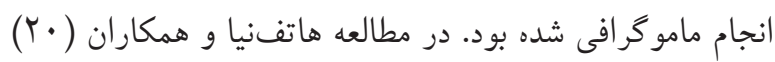

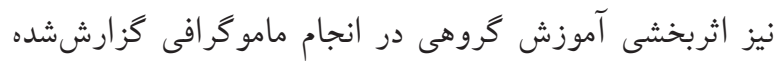

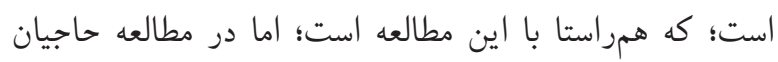

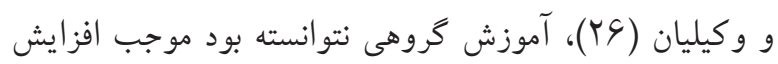

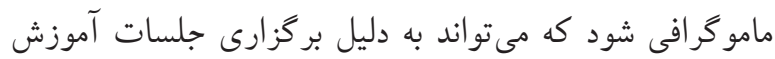

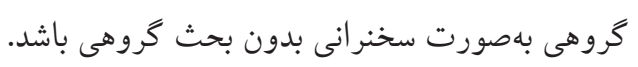

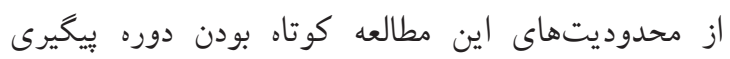

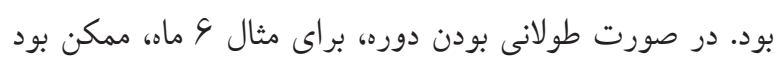
افراد بيشترى زمان كافى براى انجام مامو كرافى بيدا مى كردند.

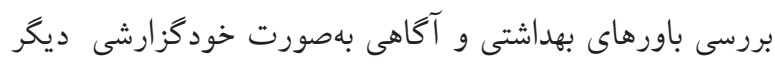

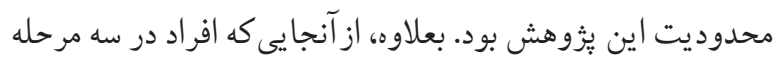

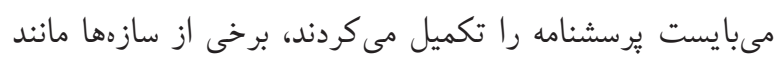

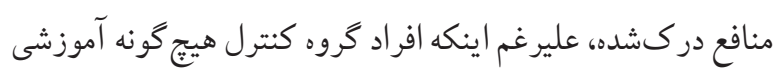

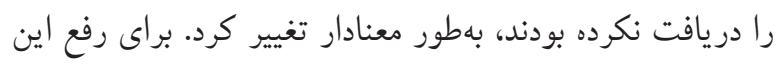

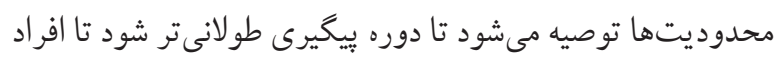


5. Azizi F, Janghorbani M, Hatami H. Epidemiology and Control of Common Diseases in IRAN. 3rd ed. Tehran: Research Institute For Endocrine Sciences Shahid Beheshti University Of Medical Sciences; 1389.

6. Rutledge DN, Barsevick A, Knobf MT, Book binder M. Breast cancer detection: Knowledge attitudes and behaviors of women from Pennsylvania. Oncol Nurs: Forum 2001; 28(6): 1032-40.

7. Mousavi SM, Montazeri A, Mohagheghi MA, Jarrahi AM, Harirchi I. Breast cancer in Iran: an epidemiological review. Breast J 2007; 13(4): 383-391.

8. Ameri R. Surveying the knowledge of women aged above 15 year reffering Ghods birth hospital about cancer screening methods. MD Thesis, Zahedan University of Medical Sciences. Faculty of medicine, 2002.

9. Chong PN, Krishnan M, Hong CY, Swan TS. Knowledge and practice of breast cancer screening amongst public health nurses in Singapore. Singapore Med J. 2002; 43(10): 509-516.

10. Ohuchi N, Yoshida K, Kimura M, Ouchi A, Kamioki S, Shiiba $\mathrm{K}$ and et al. Improved detection rate of early breast cancer in mass screening Combined with mammography. Jpn J Cancer Res 1993; 84(7): 807-812.

11. Chua SM, Mok T SK, Kwan WH, Yeo W, Zee B. Knowledge, perceptions and attitudes of Hong Kong Chinese women on screening mammography and early breast cancer management. Breast J 2005; 11(1): 52-56.

12. Farshbaf Khalili A, Shahnazi M. Breast cancer screening (breast self-examination, clinical breast exam, and mammography) in women referred to health centers in Tabriz, Iran. Indian J Med Sci 2010;64(4): 149-162. (Persian)

13. Mahoori KH, Sadeghi Hasanabadei A, Talei AR. Knowledge and practice of women referring to Shiraz health centers about breast cancer screening. Med J Hormozgan 2003;7:68-75. (Persian)

14. Salimi Pormehr S,Kariman N,Sheykhan Z, Alavi Majd H.TEST Investigation of Breast Cancer Screening Performance and Affecting Factor in Women Refferd to Ardebils Health and Medical Centers, 2009. J Ardabil Univ Med Sci 2010;10(4): 310-318. (Persian)

15. Karayurt O, Dramali A. Adaptation of Championss Health Belief Model Scale for Turkish women and evaluation of the selected variables associated with breast selfexamination. Cancer Nurs 2007; 30 (1):69-77.

16. Canbulat N, Uzun O. Health beliefs and breast cancer screening behaviors among female health workers in Turkey. Eur J Oncol Nurs 2008; 12 (2): 148-56.

17. Avci IA, Gozum S. Comparison of two different educational methods on teachers) knowledge, beliefs and behaviors regarding breast cancer screening. Eur J Oncol Nurs 2009; 13(2): 94-101. https://www.researchgate.net/profile/ Ilknur_Aydin_Avci2/publication/24028624_Comparison of_two_different_educational_methods_on_teachers'_ knowledge_beliefs_and_behaviors_regarding_breast_ cancer_screening/links/54d1fcde0cf25ba0f04228b0.pdf

18. Aydin IA. Factors associated with breast selfexamination practices and beliefs in female workers at a Muslim community. Eur J Oncol Nurs 2008; 12: 127-33.

19. Vahedian-Shahroodi M, Elaheh L-m, Esmaily $H$, Tehrani $\mathrm{H}$, Hamidreza $\mathrm{M}-\mathrm{H}$. Prediction of osteoporosis preventive behaviors using the Health Belief Model. Iranian Journal of Health Education and Health Promotion. 2014;2(3):199-207.

20. Hatefnia E, Niknami S, Bazargan M, et al. Correlates of mammography utilization among working Muslim Iranian women. Health Care Women Int 2010; 31: 499-514.

21. Farshbaf Khalil, Shahnazi M. Breast Cancer Screening (Breast Self-Examination, Clinical Breast Exam, And Mamography) In Women Referred To Health Centers In Tabriz, Iran. Indian J Med Sci 2010; 64(4): 149-162.

22. Rezaeian M, Sharifirad G, Mostafavi F, Moodi M, Abbasi $\mathrm{MH}$. The effects of breast cancer educational intervention on knowledge and health beliefs of women 40 years and older, Isfahan, Iran. J Edu Health Promot 2014; 3:4- 10.

23. Karimy M, Hasani M, Khoram R, Ghaffari M, Niknami S. The Effect of Education, Based on Health Belief Model on Breast Self- Examination in Health Liaisons of Zarandieh City. Zahedan J Res Med Sci 2008; 10(4):283-291.

24. Taymoori P, Berry TR. The validity and reliability of Champion's Health Belief Model scale for breast cancer screening behaviours among Iranian Women. Cancer Nurs 2009; 32:465-72.

25. Gursoy AA, Hindistan S, Nural N, Kahriman I, Yilmaz $\mathrm{F}$, Yigitbas $\mathrm{C}$, et al. Comparison of three educational interventions on breast self-examination knowledge and health beliefs. Asian Pac J Cancer Prev 2009; 10(5): 765-72.

26. Hajian S, Vakilian K. Effects of education based on the health belief model on screening behavior in high risk women for breast cancer, Tehran, Iran. Asian Pac J Cancer Prev 2011; 12: 49-54.

27. Hall CP, Wimberley PD, Hall JD, Pfriemer JT, Hubbard EM, Stacy AS, et al. Teaching breast cancer screening to African American women in the Arkansas Mississippi river delta. Oncol Nurs Forum 2005; 32:857- 63.

28. Moodi M, Norozi E, Rezaeian M, Mostafavi F, Sharifirad Gh. Comparing the Effectiveness of Three Educational Interventions based on Health Belief Model on Mammography Screening Behaviors in Women above 40 Years in Isfahan, Iran. J Health Syst Res 2013; 9(4): 385-94.

29. Ceber E, Turk M, Ciceklioglu M. The effects of an educational program on knowledge of breast cancer, early detection practices and health beliefs of nurses and midwives. J Clin Nurs 2010;19: 2363- 71.

30. Gozum S, Karayurt O, Kav S, Platin N. Effectiveness of peer education for breast cancer screening and health beliefs in eastern Turkey. Cancer Nurs 2010;33:213- 20 